\title{
A Quantitative Relationship Analysis of Industry Shifts and Trade Restructuring in ASEAN Based on Multiregional Computable General Equilibrium Models
}

\author{
Luyuan Xu (iD ${ }^{1,2}$ \\ ${ }^{1}$ School of Management, Fudan University, Shanghai 200433, China \\ ${ }^{2}$ School of Economics and Trade, Guangxi University of Finance and Economics, Nanning, Guangxi 53000, China \\ Correspondence should be addressed to Luyuan Xu; xuluyuan@fudan.edu.cn
}

Received 4 December 2020; Revised 18 January 2021; Accepted 25 January 2021; Published 5 February 2021

Academic Editor: Wei Wang

Copyright (C) 2021 Luyuan Xu. This is an open access article distributed under the Creative Commons Attribution License, which permits unrestricted use, distribution, and reproduction in any medium, provided the original work is properly cited.

\begin{abstract}
This paper provides an in-depth study and analysis of the quantitative relationship between ASEAN industry transfer and nuclear trade restructuring through the multiregional computable general equilibrium (CGE) model and categorizes the ten major projects and 57 subprojects covered by the ASEAN Information Port project investment into construction, information technology, and telecommunications, according to the key directions of investment. We design and simulate the changes in production activities, trade activities, and the balance of payments behaviour of the national economy affected by the project's investment under 10 types of investment amount scenarios and prepare the corresponding social accounting matrix (SAM). Increased trade openness increases external risks and instability of the economy and fiscal revenues. At the same time, it creates other potential problems for the country such as environmental pollution and leading to unfair competition. Under free trade conditions, some manufacturers may choose to produce inputs that are not environmentally friendly to reduce costs, thereby harming the environment. For infant industries, if the government does not provide them with short-term protection or supportive policies, these new or developing infant industries may not have strong international competitiveness and may be vulnerable to the attacks of mature industries in the world. Therefore, based on the study of the influence of tax policy on trade openness, this paper examines the impact of changes in trade openness on a country's economic environment and takes tax revenue as an example to conduct an empirical analysis and improve the factors that need to be considered when adjusting tax policy.
\end{abstract}

\section{Introduction}

Most of the ASEAN countries are coastal countries, ASEAN is at the heart of maritime transportation, and the sea is an important link in building an ASEAN community of interests [1]. With the advancement of construction, maritime connectivity is an important way to strengthen the development of regional economic and trade cooperation and to achieve the goal of mutual benefit and a solution where everyone benefits for both sides [2]. In recent years, after ASEAN became a strategic partner, the economic and trade cooperation relationship between the two sides has been greatly enhanced [3]. Together with the establishment of the ASEAN Free Trade Area (AFTA) and the continued promotion of the ASEAN Economic Community (AEC),
ASEAN has become the largest trading partner of ASEAN, and ASEAN is China's third-largest trading partner and the second-largest source of imports [4]. As we all know, shipping trade will promote the development of bilateral economic trade, and economic development will, in turn, promote shipping trade, thus ushering in new vitality in the construction of ASEAN maritime connectivity, and accelerating the construction of maritime connectivity has become a priority area and key direction for economic and trade cooperation between the two sides [5]. The goal of developing countries is to achieve trade liberalization by reducing tariffs and increasing trade openness [6]. The high frequency of international trade activities also brings some negative impacts such as the decline in government revenue from trade taxes [7]. In many developed countries, the 
domestic tax base is stable and the loss of government revenue can be offset by raising sales taxes on products [8]. However, in less-developed or developing countries, the revenue constraint on trade openness may affect the promotion of trade liberalization policies [9]. On the other hand, tax policies that expand trade openness should be studied in conjunction with an analysis of government expenditures to maintain a balanced government budget [10]. The domestic risks associated with trade openness can be adjusted by government spending policies to maximize the benefits of trade openness while minimizing its negative effects [11]. Therefore, it is important to study the economic impact of trade openness on tax revenue, import and export trade, and social welfare in conjunction with other economic policy measures when examining tax policies to expand trade openness [12].

Foure takes infrastructure in connectivity as the object of his study and argues that ASEAN infrastructure construction is conducive to improving and strengthening bilateral relations between China and ASEAN and also has a certain role in promoting China's own investment and trade, which has a profound impact on the economic and political stability of both sides [13]. The problems and obstacles that exist at the time of this project include the lack of sufficient political trust between the two sides and the fact that the construction of connectivity is a major project that costs a lot of money and faces certain financial shortfalls in the process of construction, as well as the regulatory construction between different countries and regions [14]. As pointed out by Mr. Wei, in terms of the political and economic stability of the two sides, the construction of connectivity can, to a large extent, promote the stable and sustainable development of cooperation between the two regions [15]. At the same time, there are also some problems and challenges in building connectivity, such as China's economic strength and scale are relatively stronger than those of ASEAN countries, which has caused some ASEAN countries to worry; building maritime connectivity will affect the interests of extraterritorial powers, which will lead to intervention, the inconsistencies in customs systems and standards between China and ASEAN countries, and the lack of consistency in the customs regulations and standards between China and ASEAN countries, as well as the lack of coordination between the two countries [16]. The difficulties are caused by the differences among ASEAN countries. Ma puts forward corresponding countermeasures and recommendations through his study on the development of connectivity between China and ASEAN [17]. As maritime connectivity requires abundant financial reserves, to solve the problem of a single financing channel; the paper points out that both sides should make full use of interregional financial arrangements and constantly explore new financing channels [18]. At the same time, the two sides should actively adopt a variety of cooperation methods to accelerate the cooperation between China and ASEAN countries in the maritime industry and strive to develop practical cooperation between the two sides [19]. According to Seyedmashhadi, through his research on this topic, he believes that maritime connectivity is a major engineering project involving many fields and sectors, so to achieve the goal of building connectivity between the two sides, political support from regional governments is needed, and at the same time, it is necessary to coordinate the interests and demands of all relevant parties to consolidate the cooperation mechanism related to connectivity [20].

The significance of this paper lies in the fact that the current theoretical and empirical studies on the regional economic impact of large-scale construction projects are still very weak. Based on the literature of major project construction evaluation theory and methodological research, this paper summarizes and clarifies the development trend of a regional economic impact evaluation of major project construction and proposes an evaluation method suitable for this study, which will help standardize the regional economic impact evaluation of major project construction. On the contrary, the three tax rate simplification schemes in this paper, although not as effective as Scheme 1 and Scheme 2 in promoting the transformation and upgrading of industrial organizations, have a good effect on the income level of residents and enterprises. The ASEAN Information Port construction project is a new and large-scale project, but no quantitative economic impact estimation study has been seen so far. This paper attempts to scientifically measure and quantify the impact of the project on regional economic growth, industrial structure, employment, and so forth based on the CGE model to analyse the economic benefits of the project to enhance the scientific basis for decisionmaking and provide a reference for related policy formulation and research.

\section{Quantitative Relationship Analysis of the CGE Model of ASEAN Industry Shift and Trade Restructuring}

2.1. CGE Modeming. The standard static CGE model is a global study of the economic behaviour of all economic sectors, economic agents, and institutions in a single country over a certain period, which has the effect of changing all the data values in the model to reflect the global changes resulting from a policy change by changing a certain set of data values as an economic shock to the policy [21]. It is a typical quantitative economic analysis method, widely used in the fields of economic growth, structural adjustment, international trade, public finance, income distribution, agriculture, climate change, resources and environment, and other policy analysis. It is based on strict microeconomic theory, constructs a free and competitive market environment, describes the relationship between various sectors of the national economy and various accounting accounts, simulates the operation of macroeconomic systems and price adjustment mechanisms, simulates and predicts the effects of policies and economic activities, and examines the effects and impacts of various policy instruments. The core economic relationships of general equilibrium theory are shown in Figure 1. 


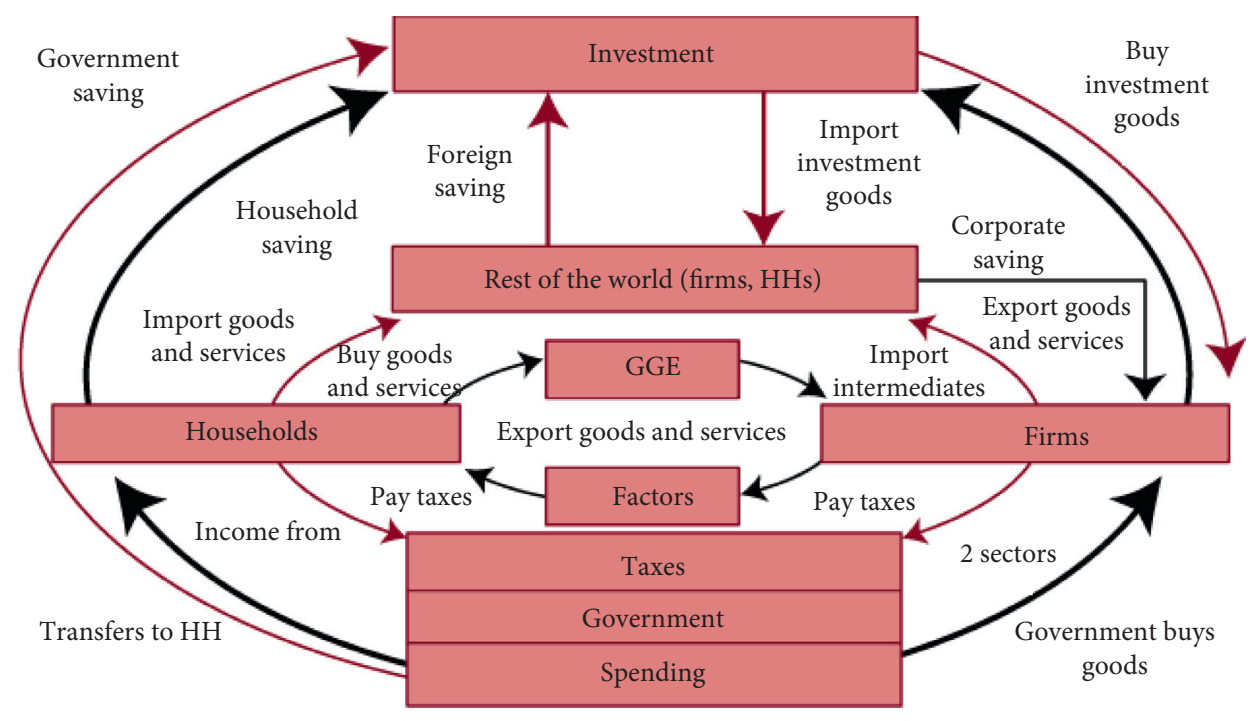

Figure 1: CGE model design.

The standard CGE model has the following main characteristics: it builds data based on input-output tables; it regulates the equilibrium of commodity and factor markets through relative prices; it assumes homogeneous subjects, heterogeneous sectors, free competitive markets, constant returns to scale, like-kind preferences, and obedience to Walras's law; it allows substitution of products or factors at different levels of the hierarchy, and it allows production techniques to be influenced by changes in relative prices [22].

CGE is a newly developed economic model that can be applied to many research fields and can give practical policy recommendations. Different from other early empirical models, the CGE model is a macroeconomic model based on neoclassical microtheory and internally consistent. Because the CGE model can be used to comprehensively evaluate the effects of policy implementation, in recent years, many developing and developed countries have begun to use this model to evaluate the effects of energy crises and tax and trade policy reforms. Economists recognize that various policies may have important general equilibrium effects, so they continue to improve economic models to make it more conducive to analyse the potential effects of various policies.

The former focuses on economic characteristics such as full factor employment, price regulation, and savings drive, while the latter advocates economic characteristics such as incomplete employment, price stickiness or rigidity, and investment drive. According to the regional classification, the CGE model can be divided into the single-region model and multiregion model. The multiregion model is more complex than the single-region model because it needs to consider the interconnections between regions. Depending on the purpose, CGE models are constructed as public finance models, income distribution models, labour transfer models, structural adjustment models, international trade models, economic growth models, regional economic development models, environmental resource policy models, sustainable development models, and so on [23]. In short, there are various variations of the CGE model depending on the research needs for different model designs.

The production module is a description of the optimal decision-making of factor inputs and intermediate inputs to production activities in the commodity production sector, using production techniques with constant returns to scale and based on the principle of cost minimization. In the production module, the production function is divided into six nested levels and the upper level of the production function CES function expression in the following equation:

$$
F(x, y)=\left\{\begin{array}{lc}
\operatorname{Cr}\left(x_{i}, y_{j}\right), & 0<x<0.2, \\
\operatorname{Sr}\left(x_{i}, y_{j}\right), & 0.2 \leq x<0.5 \\
\operatorname{Nr}\left(x_{i}, y_{j}\right), & 0.5 \leq x \leq 1 .
\end{array}\right.
$$

From microeconomics, the agents of the production economy will determine the quantity of output QAG by minimizing the input cost $C$. Therefore, the following linear planning optimal solution can be established:

$$
\mathrm{DCG}= \begin{cases}D_{i+1, j}, & i=1, \\ \mathrm{DCG}_{i-1, j+1}+\frac{D_{i}}{\lg _{2}(i)}, & \text { otherwise. }\end{cases}
$$

Using the LaGrange multiplier solution and differential solution, the $i$ condition for cost minimization is finally obtained as follows:

$$
\text { DCG }=\frac{\mathrm{DCG}_{k}}{1+\sum_{i, j=1}^{\left|C_{i, j}\right|}\left(1 / \lg _{2}(i, j)\right)} .
$$

Similarly, the expression for the value-added function Rot is also a reference to CES, while the Lyontiv function represents the consumption of intermediate inputs as follows: 


$$
\begin{aligned}
& T_{i}^{j}=A_{i-1}=\operatorname{Trans}\left(a_{i-1}, 0,0\right) \operatorname{Rot}\left(x_{j-1}, a_{i-1}\right) \operatorname{Trans}\left(0,0, d_{j}\right) \operatorname{Rot}\left(z_{i}, \theta_{j}\right), \\
& \frac{\partial L}{\partial a}=\sum_{i=1}^{n}\left[y_{i}-\frac{L}{A} \frac{\exp \left(a+\sum_{j=1}^{m} x_{i+1, j} \beta_{j}\right)}{1+\exp \left(a+\sum_{j=1}^{m} x_{i j} \beta_{j}\right)}\right]=0 .
\end{aligned}
$$

The CATHECTED system involves three economic agents: residents, enterprises, and the government. The income and expenditure of these three economic agents can be divided into two stages, the primary distribution stage: firstly, residents and enterprises pay factors in production activities to obtain income; secondly, residents and enterprises pay taxes to the government; the remaining part is used for consumption and savings, and the government receives taxes, and then the national income is distributed to the government. The distribution stage: the government transfers a portion of its income to residents and firms through public spending and other means; residents and firms receive subsidized benefits; and the rest is used for government consumption and savings. The equilibrium system is mainly to meet the system equilibrium and system equilibrium; the market is a perfectly competitive market, under the behaviour of rational economic agents; and the market is finally equilibrium, that is, market liquidation. This mainly includes factor market liquidation, the balance of payments, and investment-savings balance. Under these constraints, it is possible to calculate the market equilibrium point in the ideal state [24].

The host institution module is divided into three main entities: residents, enterprises, and the government and foreign countries. By providing labour and capital, residents receive transfer payments such as wages and profits from enterprises and consume the goods they need to obtain them. Taxes are levied to generate revenue, a portion of which is used to subsidize residents and businesses or to purchase goods; foreign and domestic economic activities are mainly import and export transactions of goods and transfer payments to residents, as shown in Table 1.

The port development of China and most ASEAN countries have been accelerating, but the quality of port infrastructure in ASEAN countries is generally not high, except for Singapore and Malaysia, which have relatively perfect maritime customs clearance, port facilities, and equipment. The high quality of port infrastructure in Singapore and Malaysia is mainly attributed to their geographical advantage of being located on the main transportation routes in Malacca, plus the government's emphasis on the construction and development of port infrastructure. From the container throughput data, the overall level of port cooperation between China and ASEAN countries is not high, which will certainly affect the maritime connectivity of both sides.

\subsection{Quantitative Relationship Analysis of Trade Restructuring.} The construction of maritime connectivity is a major project that requires a large amount of financial support and therefore requires a certain level of financing capacity on both sides. The large financing gap is a major challenge for both sides and a problem that needs to be solved. As we all know, in the process of promoting the construction of maritime connectivity, the interconnection of port and shipping infrastructures inevitably requires large amounts of capital investment and strong support from relevant government departments. As we all know, the connectivity project is a major project, and accordingly, it has some obvious characteristics, that is, large capital requirements and relatively long project completion time, which may discourage private capital from joining the project and investing in it. As a result, it is difficult for ASEAN countries to finance their infrastructure projects, which increases the financial pressure and risk to a large extent. However, this is still far from enough, so both sides should work together to solve the problem of capital shortage by financing the construction through different channels and establish a strong and effective investment and financing platform to promote the construction of maritime connectivity between the two sides [25]. At present, there is still a certain gap between ASEAN countries in terms of port cargo handling efficiency, seabed exploration technology, transportation equipment, and port construction and operation. Most of the port infrastructure equipment in ASEAN is old, which makes it difficult to provide timely and efficient services. Therefore, both sides need to continue their efforts in upgrading infrastructure technology, as shown in Figure 2.

With "hard connectivity" reducing transportation costs by $50 \%$ and "soft connectivity" reducing customs standards and mechanisms by $10 \%$, the output of China's textile and garment and light industry sectors have increased to a certain extent, with the textile and garment industry showing the greatest increase in output. The textile industry increased by $0.19 \%$, followed by the light industry by $0.09 \%$. This is because the textile industry is typically labour-intensive and China has a clear comparative advantage. The ASEAN maritime connectivity will make the market more open and boost China's exports in this industry. Vietnam's textile and garment sector saw the largest increase of $23.83 \%$, while exports also increased significantly (33.12\%). The output of the textile sector in the rest of ASEAN countries will be impacted to varying degrees. According to the current level of industrial development in China, light industry is still attached to labour-intensive industries and China's population base is large, has more people with labour capacity, and has a comparative advantage in the textile industry, so output increased by $0.09 \%$ and exports also increased by $0.42 \%$. The light industry output of ASEAN countries declined to different degrees, but also because of the existence of better labour advantages, Indonesia and Vietnam's light industry exports still increased by $0.19 \%$ and $2.67 \%$, respectively. Light industrial output in Japan and Korea increased by $0.87 \%$, while exports increased by $2.14 \%$. Light industrial 
TABLE 1: Container throughput capacity of ASEAN ports.

\begin{tabular}{lcc}
\hline Rank & Country & Port $(10,000$ tons $)$ \\
\hline 1 & Singapore & 3415.68 \\
2 & Malaysia & 2358.45 \\
3 & Vietnam & 856.6 \\
4 & Thailand & 685.4 \\
5 & Philippines & 598.5 \\
6 & Indonesia & 124.8 \\
7 & Cambodia & 113.5 \\
8 & Myanmar & 85.47 \\
9 & Brunei & 56.4 \\
10 & Laos & 12.5 \\
\hline
\end{tabular}

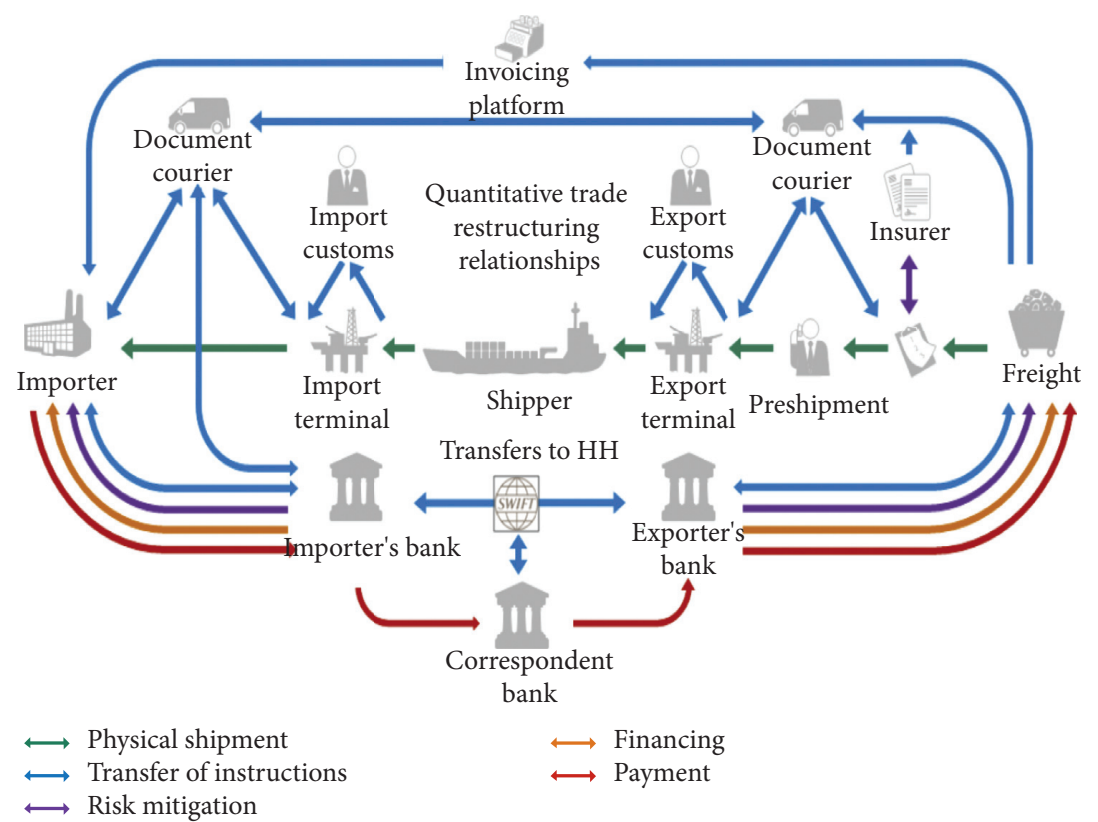

FIGURE 2: Quantitative trade restructuring relationships.

output in the United States, the EU, and the rest of the world remained essentially unchanged, while imports and exports declined. Also, China's output decreased in processed food and heavy industry, with processed food output decreasing by $0.21 \%$ and heavy industry output decreasing by $0.03 \%$. Heavy industries, which are usually classified as capital-or technology-intensive industries and do not have a comparative advantage over China, were somewhat impacted, and import demand for heavy industries increased by $3.41 \%$. In ASEAN countries, output in both processed food and heavy industry sectors was affected differently, with Singapore and Malaysia experiencing an increase in output in both sectors, with Singapore recording the largest increase in heavy industry (3.76\%) and Malaysia recording the largest increase in processed food $(1.72 \%)$. Both heavy industry imports and exports of ASEAN countries increased to varying degrees, with the Philippines experiencing the largest increase in heavy industry exports of 9.52\%. This shows that the ASEAN maritime connectivity is conducive to the development of heavy industry on both sides. Japan, South Korea, the United States, Europe, and the rest of the world have all increased their output of processed food. In the heavy industry sector, although the United States and the
European Union are not countries along the Maritime Silk Road, these countries and regions are rich enough in the capital and mature technology to occupy a leading position in the heavy industry sector, and their output continues to increase by $0.16 \%$. However, due to the trade transfer effect generated by the construction of ASEAN maritime connectivity, the heavy industry exports of Japan, Korea, and the US and Europe slowed down, declining by $1.44 \%$ and $0.44 \%$, respectively.

In the modelled goods market, the goods produced by domestic production activities are divided into two parts in the sales chain: domestic supply sales and exports. Also, the goods sold in the domestic market are composed of both domestic production, domestic sales, and imports. The price of imported goods is determined by the international market price, exchange rate, and tariff. The structure of the foreign trade module is shown in Figure 3.

In Figure 3, the content and information involved in foreign trade are more complicated. If you consider other trades, the results will be inaccurate. Systemic equilibrium is a state of market liquidation, where supply and demand are equal in all domestic markets, where the domestic market supply of goods equals domestic aggregate demand for goods, 


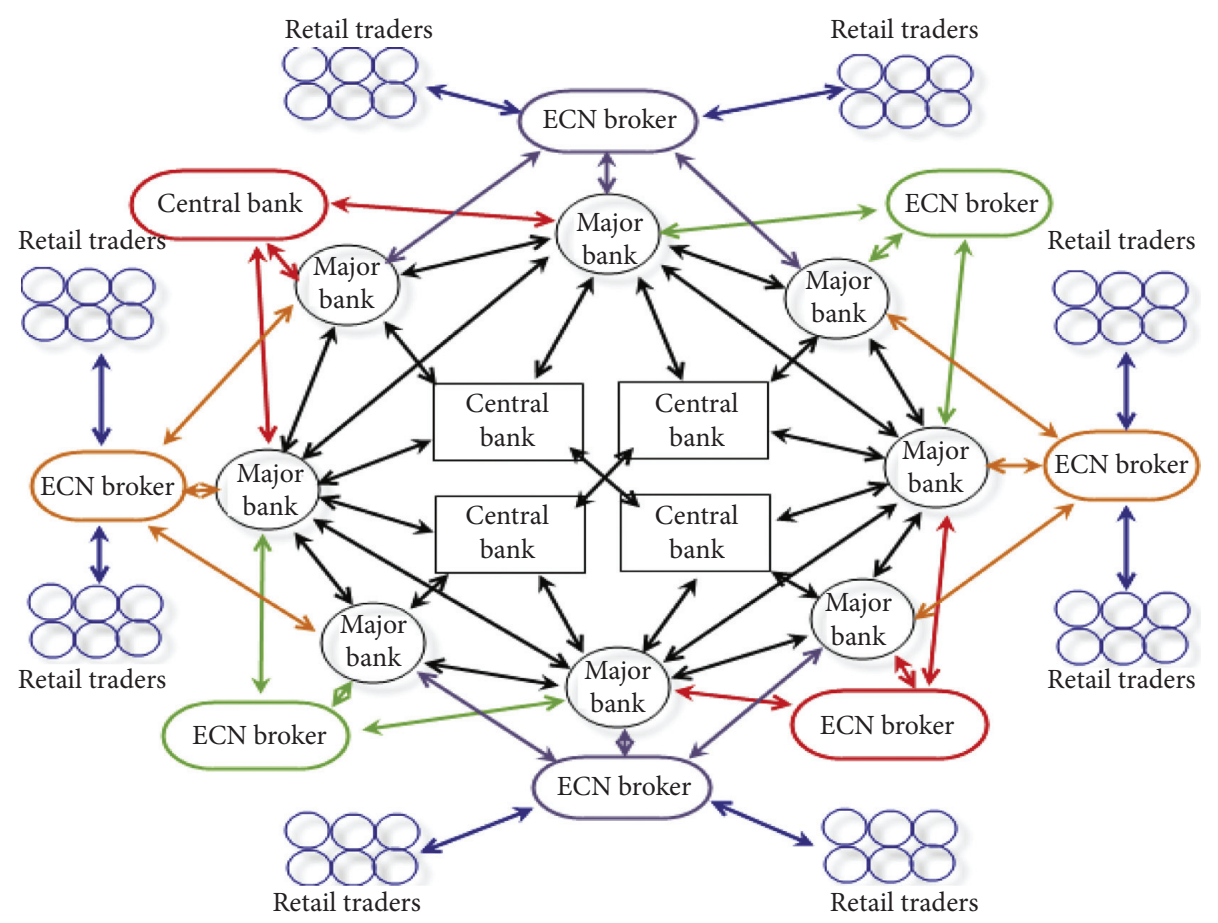

FIGURE 3: Schematic diagram of the foreign trade module structure.

aggregate demand for labour equals the aggregate supply of labour, aggregate demand for capital equals the aggregate supply of capital, aggregate investment equals aggregate savings, and international income equals international expenditure. This account depicts the specific activities of each sector of production in an open economy. Horizontally, it represents the total output of each sector; vertically, it represents the inputs of each sector in each production activity, including intermediate and factor inputs, which, when added together, constitute the total cost of that production activity. This account depicts the supply and demand situation in domestic commodity markets. Horizontally, it represents the demand for goods from different sectors, including the consumption of various economic agents and intermediate inputs, which together constitute the total demand; vertically, it represents the various sources of supply in the domestic commodity market, consisting of domestic production, domestic sales, and imports. The account must satisfy the equality of aggregate supply and demand. The capital and labour accounts, which belong to the factors of production account, depict the supply and demand in the market for the two factors. In this account, the horizontal representation of the factor rewards from the various production activities describes the various sources of factor income; also, the vertical representation shows the distribution of factor income among institutions, that is, the destination of factor expenditures. From the overall point of view, each factor is required to reach a state of equal total supply and demand.

\section{Analysis of Industry Transfer Structure}

3.1. Design of Industry Transfer Structure. Next, consider the effects of the different VAT rate simplification schemes on the gross value added of industries: first, all three rate simplification schemes reduce the value-added of primary industries by $-0.6163 \%,-0.4772 \%$, and $-0.3516 \%$, respectively; second, all three rate simplification schemes increase the value-added of secondary industries by $2.4101 \%$, $-0.4772 \%$, and $-0.3516 \%$, respectively; second, all three rate simplification schemes increase the value-added of secondary industries by $2.4101 \%,-0.4772 \%$, and $-0.3516 \%$, respectively. Finally, the analysis of the impact of the three scenarios on the value-added of the tertiary sector shows that Scenario 3 increases the gross value added of the tertiary sector by $0.0256 \%$, while Scenarios 4 and 5 both decrease the gross value added of the tertiary sector. When considering the impact of different scenarios on employment, it is found that all three scenarios will reduce employment in the primary and tertiary industries and increase employment in the secondary industry. Therefore, taking into account the effects of different simplification schemes on the three industries, the three VAT rate simplification schemes designed in this paper are not as effective as Scheme 1 and Scheme 2 in promoting the transformation of traditional industries and the structural upgrading of industries, as shown in Figure 4.

In this paper, the impact of Scenario 1 is subdivided into various industries, and the financial, leasing and business services, accommodation, transportation, real estate, and construction industries are selected for further comparative analysis. It is found that Scenario 1 is beneficial to increasing the gross value added of the real estate, accommodation, and catering, and financial services industries, but not to increasing the gross value added of the construction and transportation industries. The difference between the two schemes is mainly the difference in parameter settings. In the figure, we just compared the settings of two different 


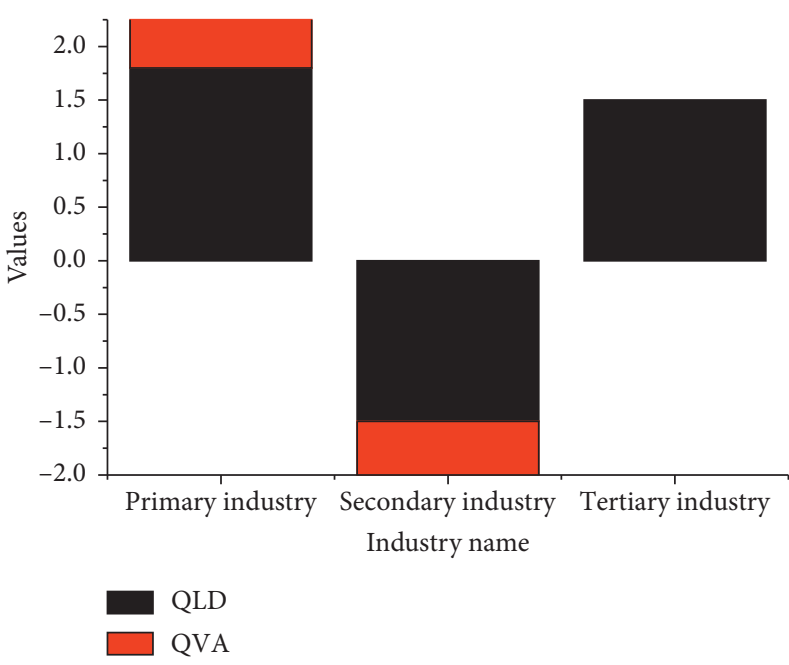

(a)

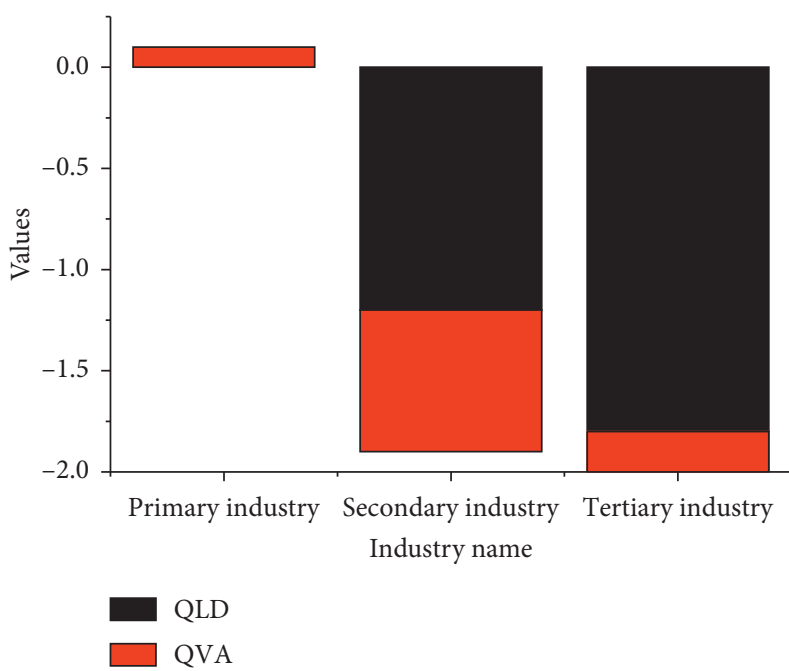

(c)

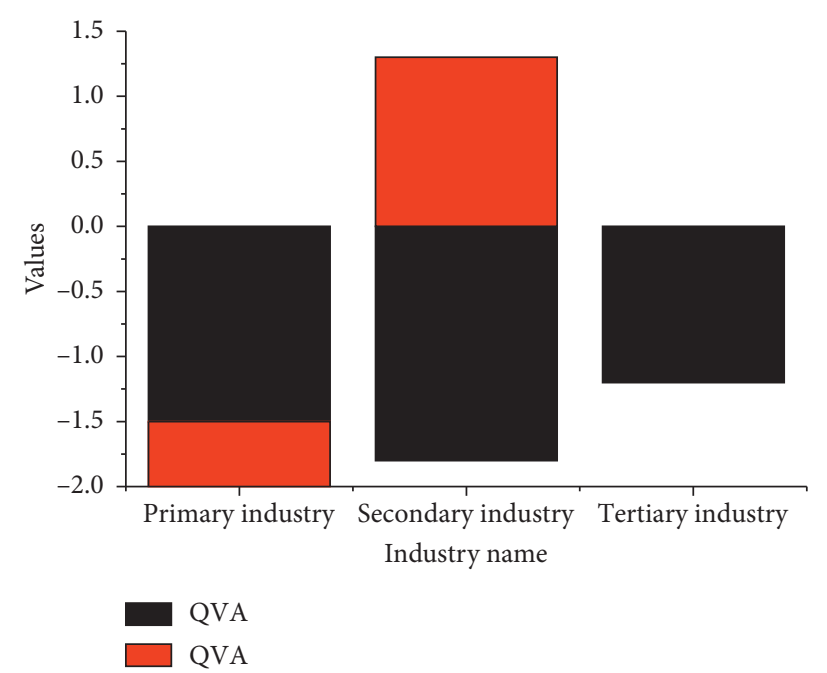

(b)

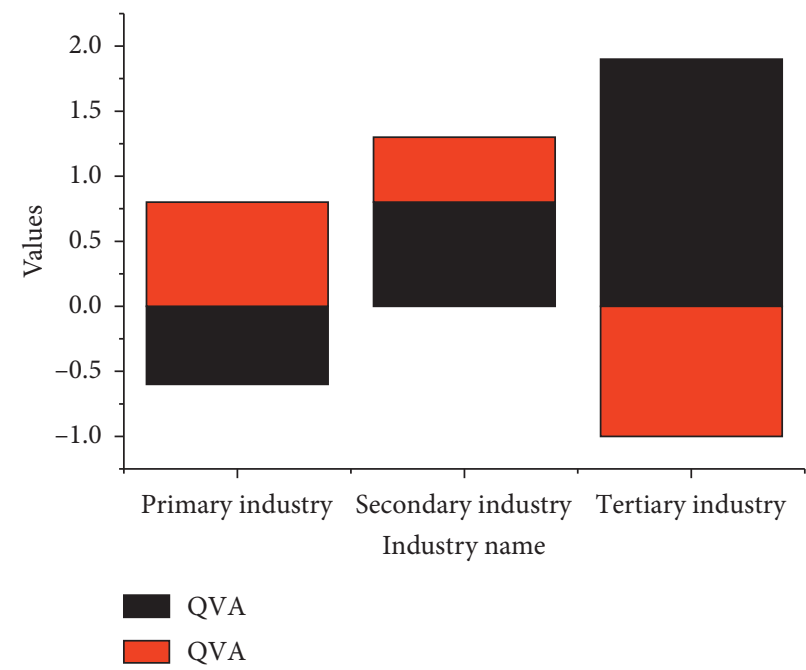

(d)

FIgURE 4: Structural impact of different simplification scenarios on three industries.

parameters and there is a big difference. Scenario 4 is conducive to increasing the industrial added value of the accommodation, leasing and business services, finance, and real estate industries, but is not conducive to increasing the industrial added value of the transportation and construction industries. Option 5 is favourable to increasing the total value added of the real estate industry, leasing and business service industry, and finance industry, but unfavourable to increasing the total value added of the construction industry, accommodation industry, and transportation industry.

In this paper, the income distribution effect refers to the pattern of distribution of national income among government, residents, and firms. The simulation results of the implemented policies, that is, Scenarios 1 and 2, are first analysed. Scenario 1 simulates the tax structure after the fullblown tax reform, in which the government's income level is increased and the corresponding income levels of residents and enterprises are reduced to varying degrees. Scenario 2 simulates the current VAT rate structure, in which residential income, corporate income, and government income levels are all reduced to varying degrees. When comparing Scenario 2 with Scenario 1, the former lowers the government's income level while raising the income levels of businesses and residents.

3.2. Quantitative Performance Results Design. In this paper, the national economy is divided into four major sectors based on statistical yearbooks and input-output tables, namely, primary, secondary, tertiary industries, and CAIH projects. The empirical analysis is based on the SAM table, a social accounting matrix of the CAIH-CGE model, which examines the impact of investment project "shocks" on the regional economy as a whole, and therefore the SAM table contains the commodity accounts, activity accounts, factor accounts, resident accounts, enterprise accounts, government accounts, and other social accounts. Accounts, savings and investment accounts, and foreign accounts are the 
indicators examined in the model simulation, that is, the explanatory variables. The CAIH-CGE model is a complex solution to describe the economic system with multiple systems of equations to find the optimal solution, which includes input-output, linear planning, and nonlinear planning. The General Algebraic Modeming (GAMS) model is a complex solution to describe the economic system with multiple systems of equations to find the optimal solution. General Algebraic Modeming System is an applicationoriented high-level programming language for mathematical planning, which is often used for solving CGE models. In this paper, GAMS software is also used for programming the solution. The steps are as follows: (1) model set definition and declaration; (2) social accounting matrix SAM table data input and production parameters definition and assignment; (3) model endogenous variables definition and assignment; (4) endogenous variables and model equations definition; (5) model equation definition and expression; (6) baseline variables solution, the base year equilibrium solution used to test the program; and (7) the variables debugged to improve the program and to simulate the policy. In this paper, the CAIH-CGE model complete the operation test, and the simulation of some of the main results is shown in Figure 5.

Then, the efficiency of tax administration needs to be improved, especially for the information of foreign enterprises' investment, because no law requires domestic enterprises to register their outward investment, so the foreign tax information cannot be grasped in detail. Also, under the current tax administration mode, there is a significant shortage of tax service personnel in international taxation, and there are fewer talents with complex international taxation skills, which restricts the improvement of China's tax administration and service level. In international trade, import tariff barriers include two parts, which are usually called import tariffs and special tariffs. As import tariffs have corresponding regulations and public announcements, special tariffs are targeted and easily overused, leading to retaliation from other countries. After China acceded to the WTO, its products have been frequently subjected to antidumping duties, countervailing duties, and special tariffs imposed by its trading partners. Despite the revision of China's antidumping regulations, there are still many problems with China's antidumping regulations, especially the lack of details on the identification of dumping behaviour.

Globalization is an important cause of income disparity, which in turn includes trade openness and capital market openness. Some scholars believe that increasing trade openness will lead to a larger gap between the rich and the poor, and therefore some groups will oppose continued trade openness, which will hinder the trade liberalization process. Therefore, the income distribution gap also affects the progress of tax adjustment for greater trade openness. The following is a model using the $H-0$ theory, assuming constant returns to scale, in the traditional $n \times n$ model setting:

$$
A * W \geq P * P^{w},
$$

where $w$ is the price of inputs and $P$ is the price of outputs. $a$ is an $n \times n$ matrix of technology factors. Assuming that a

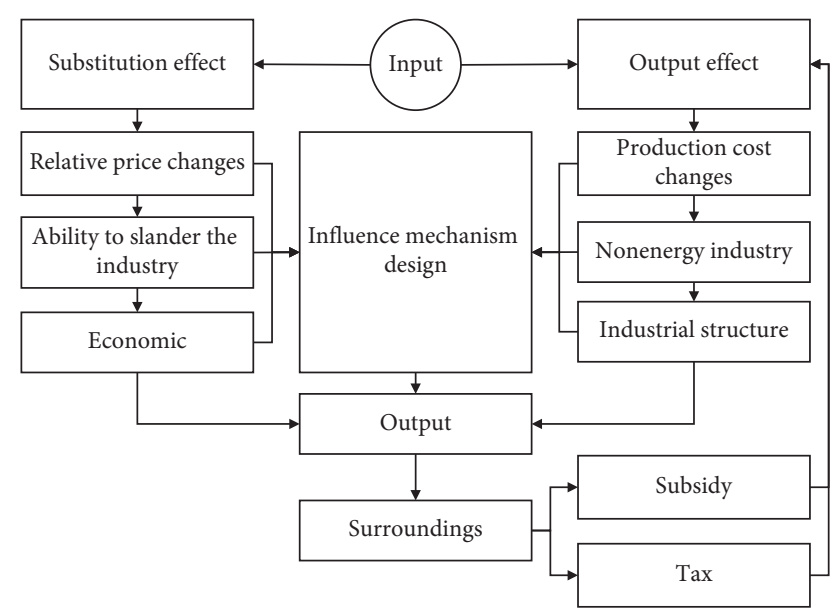

FIGURE 5: Influence mechanism design.

zero-margin situation is pursued, factor prices are determined by technology, product price, and quantity, as shown in equation (6):

$$
\begin{aligned}
W & =A^{-1} P^{*} P^{w}, \\
M^{\prime} & =\left\{M^{\prime}=m^{2}-m_{c}, \quad \forall m \in M\right\}, \\
M^{\prime \prime} & =\left\{M^{\prime \prime} \mid m^{\prime \prime}=\frac{m^{\prime} \times \mathrm{d} m}{D \cdot \mathrm{d} m}, \quad \forall m^{\prime} \in M^{\prime}\right\} .
\end{aligned}
$$

\section{Result Analysis}

4.1. Analysis of CASH Project Investment Classification Results. The CAIH project investment is a combination of several investment projects. To facilitate research and consider the purpose of CAIH project investment and industrial distribution, the subdivided projects are divided into two categories: public infrastructure construction investment and information science, education, culture, and health public management service investment (referred to as information technology). It is obvious from Figure 6 that the strongest investment is in public infrastructure, mainly in information and communication infrastructure connectivity projects, ASEAN information port base projects, technology innovation cooperation demonstration projects, and smart city demonstration projects.

Is investment the main driver of economic growth, as is the fixed asset investment in other regions? The CAIH project investment has a positive impact on regional economic growth, different investment amount scenarios are positive for the national economy to promote development, and the most direct impact is the GDP growth. In this paper, the statistical analysis of the GDP growth of the statistical yearbook, the CAEH project investment mainly takes place in 2019, and it can be assumed that if there is no ASEAN information port project investment, still follow the previous year's GDP growth rate, then the A-curve can be drawn (Figure 7). On this basis, consider the impact of the ASEAN 


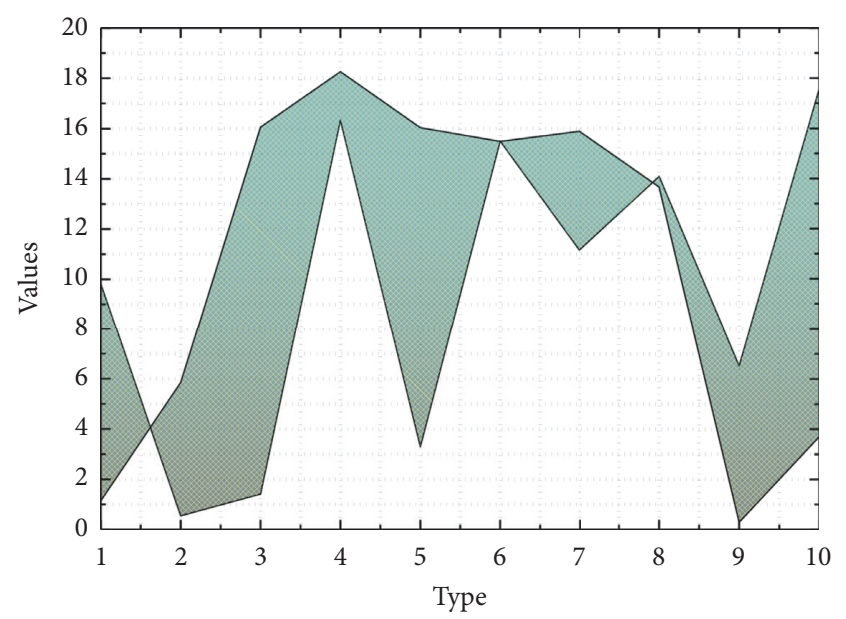

FIGURE 6: Comparison of CASH project investment by sector and $\mathrm{CB}$ industry amount.

information port project investment on GDP. When the investment occurs at $100 \%$, the project contributes $2.02 \%$ to the GDP growth.

From the analysis of evidence, the more related the industry is to the investment direction and key projects of CAIH, the more obvious the industry is affected by the "impact," and the specific industry affected by the growth rate should also consider the industry's proportion in the project. The information industry is characterized by high permeability, high drive, and high spillover and is a knowledge-intensive, multilevel, and multi-industry industry. According to the mechanism of CAIH project investment on economic development in Chapter 2, it can be seen that the project investment will affect the production and services of the sectors related to the project when it occurs, although it is difficult to count the orders of consumption of specific products and services caused by the project in the end, and it is also difficult to indicate which specific products and services with added value are indeed affected by the CAIH project investment. The AIH-CGE empirical analysis shows the macroimpact of the project on the three industries. At present, the focus of the preconstruction phase of the CAIH project is on the construction of infrastructure, which mainly involves the input of hardware such as building products and electronic equipment, which is mainly associated with the secondary industry. In terms of production activities, the empirical analysis of the consumption of factor capital of production inputs shows that the growth rate of consumption in the tertiary sector is slightly larger than that of the secondary sector, but both are much larger than that of the primary sector. In an underdeveloped region, the secondary industry is the pillar industry, followed by the tertiary industry and the secondary industry. According to this, it is the secondary industry that accounts for the largest proportion of production-consumption caused by project investment, that is, project investment has the greatest impact on the secondary industry. This shows that project investment can promote the concentration of investment factors (labour and capital) in the three industries, promote employment, increase

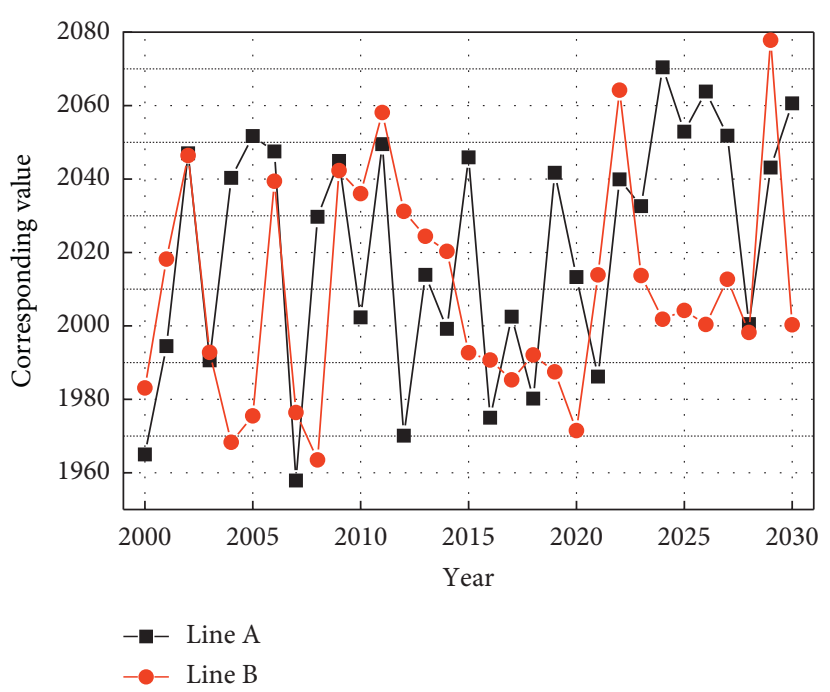

FIgURE 7: Impact of CASH project investment on GDP.

domestic demand, and expand consumption, but it is still mainly in the secondary industry, followed by the tertiary industry. In terms of trade activities, CAIH project investment has promoted the overall resource consumption, but the consumption of resources in different industries is different, with the secondary industry taking a larger share, followed by the tertiary industry and the primary industry last. The tertiary sector's export growth is greater than that of the secondary sector, indicating that the project implementation has indeed had a stronger impact on the tertiary service sector.

4.2. Analysis of CASH Project Investment Classification Results. The scenario I simulation results show that the terms of trade of China and ASEAN countries have improved to varying degrees after the ASEAN maritime connectivity, with Japan and Korea, the United States, and the EU reflecting worsening terms of trade. China's terms of trade improved by $0.053 \%$, ASEAN countries' terms of trade improved more than China's, while Japan and South Korea's terms of trade deteriorated most significantly, declining by $0.087 \%$, as shown in Figure 8. In Figure 8, we set four different parameters for the results. The main purpose of doing so is to ensure the accuracy of the results. The results of the 4 types have relatively small gaps.

The combined analysis of Scenarios I and II suggest that ASEAN maritime connectivity would improve the terms of trade between China and ASEAN countries to varying degrees and that the impact of lowering trade barriers due to consistent "soft connectivity" between China and ASEAN customs standards, regulations, and procedures would be far greater than the impact of "soft connectivity." The "hard connectivity" has brought about a reduction in transportation costs (by reducing tariffs by the same amount). Therefore, in promoting the construction of ASEAN maritime connectivity, the convergence of information, customs clearance, quality inspection, and other institutional standards should be properly grasped to make the construction 

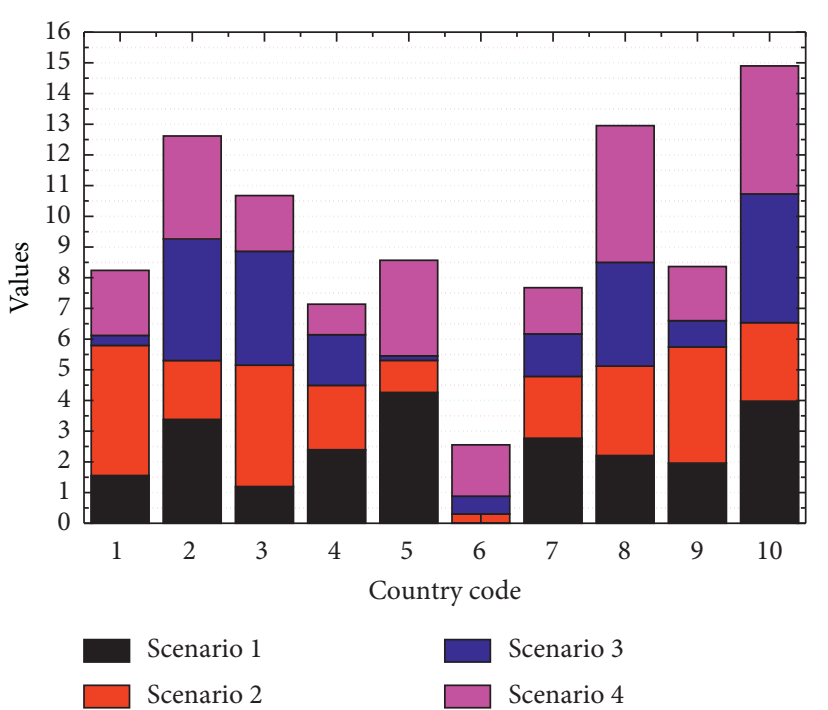

Figure 8: Changes in terms of trade by region under two shock scenarios.

of maritime connectivity between the two sides smoother and more efficient. The changes in trade conditions in each region are shown visually. According to the simulation results, in Scenario I, imports and exports of China and ASEAN countries increase, thanks to tariff reductions (equal replacement of "hard connectivity" with lower transportation costs). On the export side, the fastest growing country is Vietnam, with an increase of $2.393 \%$, as shown in Figure 9.

About GDP growth rate, in the context of the "new normal," China's economy has shifted from the longformed value orientation of "GDP growthism," and the adjustment of China's economic development is manifested in the shift from focusing on incremental expansion to revitalizing stocks and optimizing increments. Based on the structural downward shift of the long-term trend, the long-term trend of GDP is distributed between $5.5 \%$ and $7.5 \%$, and the GDP growth rate will be stable at $6 \%-7.5 \%$ with $91.5 \%$ probability; the range of GDP growth rate under the new economic normal is $4.9 \%-8.3 \%$. Thus, the GDP growth rate is set considering the characteristics of the current stage of development and relevant research literature.

The energy production structure ratio is the ratio of the total domestic output of each energy source to the sum of total energy domestic output. The four graphs in Figure 10, from left to right, from top to bottom, show how the four energy sources-coal extraction and coking products, petroleum extraction products, refined petroleum and nuclear fuel processed products, natural gas extraction products, and electricity and heat production and supply vary between 2015 and 2019

This paper argues that this change in the structure of energy production is closely related to the phenomenon of China's economic development slowdown in recent years. Since 2010, the GDP growth rate has been continuously maintained at more than $8 \%$; during this period, coal

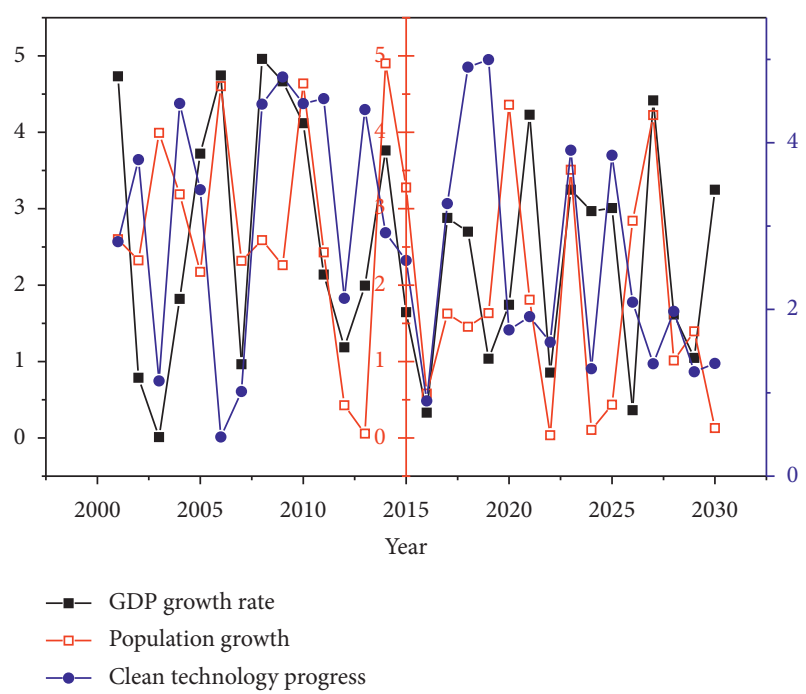

Figure 9: Baseline scenario.

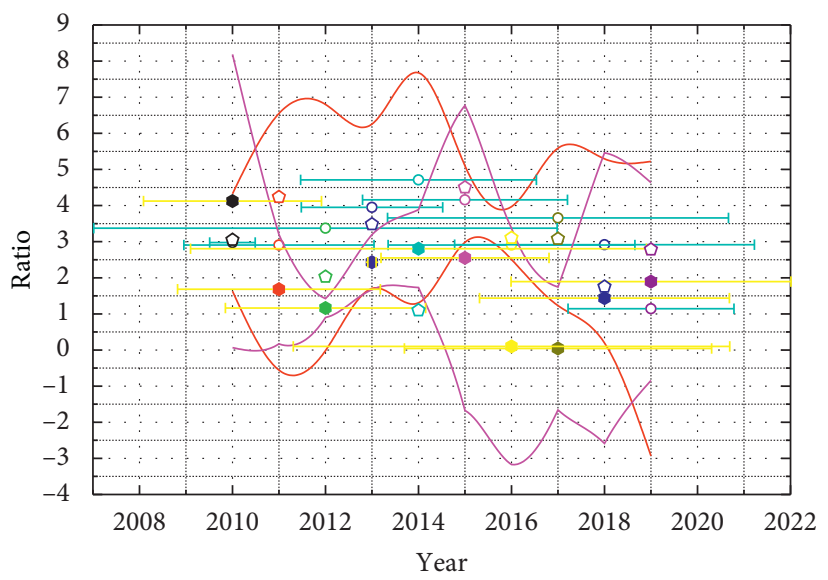

FIgURE 10: Comparison of the share of the total output of four energy types under different policy shocks.

production exceeded demand, coal prices continued to soar, and coal production increased significantly, but after 2015, the economic growth rate fell back to about 7\%, coal demand is no longer strong, such as electricity, heat production, and supply industry, iron, and steel industry, and other coal consumption declined, resulting in the construction of coal capacity ahead of the addition of Environmental pollution problems becoming increasingly severe, and environmental pressures have restricted the rapid development of coal production. At the same time, with the promotion of China's clean energy policy and the breakthrough in energy exploration technology, the production scale of natural gas has expanded continuously; the output of petroleum has increased due to the rapid growth of its demand and consumption, and the proportion of petroleum output has also expanded. A large part of the decline in the production ratio of electricity and heat is also related to changes in the structure of its consumption and demand. The proportion of output from two types of energy, electricity, and heat, is 
slowly declining, while the proportion of output from two types of energy, oil, and natural gas, is growing at a low rate.

The results of the static comparison of total investment are similar to the change in government revenue, that is, the implementation of each combination of EV incentive policies from 2015 to 2019 will result in a reduction in average total investment over the years to varying degrees, with reductions of $43.45 \%, 26.06 \%$, 51.23\%, 51.23\%, 43.45\%, 26.06\%, 51.23\%, $51.23 \%, 51.23 \%$, and $51.23 \%$ for the S1, S2, S3, S4, and S5 policy scenarios, respectively. The policy mix with $\mathrm{S} 3$ results in the largest loss in total investment, with a 4-year average reduction of $51.23 \%$. When the $\$ 4$ policy mix is implemented, the smallest reduction in total investment occurs, with an average annual loss of $21.33 \%$. The negative impact of incentives for electric passenger cars on total investment is because the incentives lead to an increase in consumption power and thus a reduction in inventories on the one hand and a decrease in the price of some related products on the other hand.

\section{Conclusion}

Based on the CGE model analysis and prediction, this paper attempts to quantitatively analyse the impact of CAIH project investment on regional economic growth, industrial structure, labour, and employment, to analyse the rationality and economic benefits of the project and enhance the scientific basis for decisionmaking. The CGE model is an important tool for simulating policy shocks, and the CAIH project is a major project that has just started. This paper attempts to explore the beginning of this malefactor, with the progress of the project work and the establishment and improvement of various basic data about the project. However, due to the high tax rate, it hurts the income levels of both residents and enterprises, especially as Scenario 1 also reduces the welfare level. On the contrary, the three tax rate simplification schemes in this paper, although not as effective as Scheme 1 and Scheme 2 in promoting the transformation and upgrading of industrial organizations, have a good effect on the income level of residents and enterprises, the total consumption level of residents, the real GDP, and the social welfare level. The third option sets the industry-wide tax rate at $8 \%$, which can maximize the real GDP, raise the income level of residents and enterprises, and improve the welfare of residents. Secondly, Option 3 reduces the current tax rate of 13\% to $9 \%$ and keeps the other tax brackets unchanged, which can also increase the real GDP, raise the income level of residents and enterprises, and improve the welfare of residents. Therefore, we believe that the current VAT rate system should continue to be reformed in the direction of simplifying the tax brackets, and the goal of simplification should be to simplify the tax rates into one bracket.

\section{Data Availability}

The data used to support the findings of this study are available from the corresponding author upon request.

\section{Conflicts of Interest}

The authors declare that there are no conflicts reported in this paper.

\section{Acknowledgments}

The study was supported by National Social Science Fund Project, China (Grant no. 18BJL049), Guangxi Philosophy and Social Science Planning Research Topic, China (Grant no. 20BJY004), https://doi.org//10.13039/501100004774 Guangxi University of Finance and Economics Maritime Silk Road and Guangxi Regional Development Research Institute Project,China(Grantno.2020XS012) and Empowerment and Educational Innovation Project of Guangxi University of Finance and Economics.

\section{References}

[1] X. Zheng and L. Jia, "An empirical study on the economic effect of financial cooperation among countries of the "silk road economic belt"” Engineering Economics, vol. 28, no. 5, pp. 542-551, 2017.

[2] H. Shahrokhi Shahraki and C. Bachmann, "Designing computable general equilibrium models for transportation applications," Transport Reviews, vol. 38, no. 6, pp. 737-764, 2018.

[3] S. Perera, M. Siriwardana, and S. Mounter, "Trade facilitationmeasurement difficulties in the computable general equilibrium model: a review," Theoretical Economics Letters, vol. 7, no. 2, pp. 154-163, 2017.

[4] R. Dellink, D. Van Der Mensbrugghe, and B. Saveyn, "Shaping baseline scenarios of economic activity with CGE models: introduction to the special issue," Journal of Global Economic Analysis, vol. 5, no. 1, pp. 1-27, 2020.

[5] M. Piskin, C. M. Hannum, and C. M. Hannum, "Constructing a multi-regional social accounting matrix for Turkey," Eurasian Journal of Economics and Finance, vol. 5, no. 4, pp. 176-196, 2017.

[6] G. Erhan Ünal, B. Karapinar, and T. Tanaka, "Welfare-at-risk and extreme dependency of regional wheat yields: implications of a stochastic CGE model," Journal of Agricultural Economics, vol. 69, no. 1, pp. 18-34, 2018.

[7] Z. Zeinali Ghasemi, S. N. Mousavi, and B. Najafi, "Effects of implementation of green tax on environmental pollutants' dispersion on macroeconomic variables: application of multiregional general equilibrium model," Caspian Journal of Environmental Sciences, vol. 18, no. 2, pp. 181-192, 2020.

[8] R. Delzeit, R. Beach, R. Bibas et al., "Linking global CGE models with sectoral models to generate baseline scenarios: approaches, opportunities and pitfalls," Journal of Global Economic Analysis, vol. 5, no. 1, pp. 162-195, 2020.

[9] T. Tanaka and J. Guo, "Realistic specifications and model predictability: testing the performance of a stochastic CGE model with regionally correlated yield variability in the wheat and rice sectors," Asian Journal of Economic Modelling, vol. 8, no. 1, pp. 55-75, 2020.

[10] E. N. Robson and V. V. Dixit, "A general equilibrium framework for integrated assessment of transport and economic impacts," Networks and Spatial Economics, vol. 17, no. 3, pp. 989-1013, 2017.

[11] M. Yamazaki and S. Takeda, "A computable general equilibrium assessment of Japan's nuclear energy policy and implications for renewable energy," Environmental Economics and Policy Studies, vol. 19, no. 3, pp. 537-554, 2017.

[12] E. Kim and Y. Yi, "Impact analysis of high-speed rail investment on regional economic inequality: a hybrid approach using a transportation network-CGE model," Journal of 
Transport Economics and Policy (JTEP), vol. 53, no. 3, pp. 314-333, 2019.

[13] J. Foure, A. Aguiar, R. Bibas et al., "Macroeconomic drivers of baseline scenarios in dynamic CGE models: review and guidelines proposal," Journal of Global Economic Analysis, vol. 5, no. 1, pp. 28-62, 2020.

[14] Y. Kunimitsu and M. Nishimori, "Policy measures to promote mid-summer drainage in paddy fields for a reduction in methane gas emissions: the application of a dynamic, spatial computable general equilibrium model," Paddy and Water Environment, vol. 18, no. 1, pp. 211-222, 2020.

[15] W. Wei, J. Zhang, B. Dong, and H. Wang, "Quantifying the impacts of China's currency depreciation and capital control: a CGE analysis," Applied Economics Letters, vol. 25, no. 14, pp. 964-967, 2018.

[16] J. Dang and Y. Pang, "Border effect of agricultural trade between China and the belt and road countries: a computable general equilibrium model analysis," International Food and Agribusiness Management Review, vol. 23, no. 1030-20201730, pp. 369-389, 2020.

[17] M. Lenzen, A. Geschke, A. Malik et al., "New multi-regional input-output databases for Australia-enabling timely and flexible regional analysis," Economic Systems Research, vol. 29, no. 2, pp. 275-295, 2017.

[18] X. Ma, H. Wang, and W. Wei, "The role of emissions trading mechanisms and technological progress in achieving China's regional clean air target: a CGE analysis," Applied Economics, vol. 51, no. 2, pp. 155-169, 2019.

[19] H. Hahm and S. Raihan, "The belt and road initiative: maximizing benefits, managing risks-a computable general equilibrium approach," Journal of Infrastructure, Policy and Development, vol. 2, no. 1, pp. 97-115, 2018.

[20] P. A. Seyedmashhadi, S. A. Jalaee, M. Nejati, and M. Zayanderodi, "Examining and comparing the economic effects of spillovers of investment risk in Iran: computable general equilibrium model approach," International Review, vol. 2017, no. 3-4, pp. 24-33, 2017.

[21] U. Johansen, R. Egging, and O. Ivanova, "Regional policy and the role of interregional trade data: policy simulations with a model for Norway," Regional Studies, Regional Science, vol. 5, no. 1, pp. 312-331, 2018.

[22] M. Winning, A. Calzadilla, R. Bleischwitz, and V. Nechifor, "Towards a circular economy: insights based on the development of the global ENGAGE-materials model and evidence for the iron and steel industry," International Economics and Economic Policy, vol. 14, no. 3, pp. 383-407, 2017.

[23] S. Zhong, J. Sha, L. Shen et al., "Measuring drought based on a CGE model with multi-regional irrigation water," Water Policy, vol. 18, no. 4, pp. 877-891, 2016.

[24] R. Wu, H. Dai, Y. Geng, Y. Xie, and X. Tian, "Impacts of export restructuring on national economy and $\mathrm{CO}_{2}$ emissions: a general equilibrium analysis for China," Applied Energy, vol. 248, pp. 64-78, 2019.

[25] S. Ismail and S. Ahmed, "Economic effects of tariff liberalization of prospective India-GCC FTA: a computable general equilibrium analysis," Foreign Trade Review, vol. 54, no. 3, pp. 224-252, 2019. 